\title{
Simulasi Pengaruh Bentuk Dinding Kapiler Divergen Terhadap Laju Aliran Isothermal Two-phase Flow Fluida Penetran Air
}

\author{
Fahim Abyan Makarim \\ Teknik Mesin, Fakultas Teknik, Universitas Brawijaya, Malang, Indonesia \\ Email: fahimam34@gmail.com
}

\begin{abstract}
Research for capillary action has been done since the early age of research and is still being done today and may also be for the upcoming time. Research about the effects of tube diameter, viscosity, and gravitation on the flow in the vertical oriented capillary tube has been done resulting in a conclusion that the bigger the diameter the slower the flow will be, with viscosity and gravitation also affected the dynamic of the flow of meniscus. In this research water as a penetrant fluid would be tested numerically by simulation software to discover the isothermal two-phase flow at vertical oriented divergent capillary pipe with upper radius varying from $0.0596 \mathrm{~cm}$, $0.0894 \mathrm{~cm}$, and $0.1192 \mathrm{~cm}$. It then concluded that agreeing with all the prior research, the bigger the radius the slower the flow will be, and also a tendency of decreasing indifference of the slope of each tube size are found together with the growth of the tube radius.
\end{abstract}

Keywords: Axis symmetry, Capillary tube, Isothermal two-phase flow, Simulation, Water.

\begin{abstract}
Abstrak
Penelian terhadap kapilaritas telah dilakukan sejak lama dan masih berlangsung hingga saat ini serta untuk waktu yang akan datang. Penelitian mengenai pengaruh diameter pipa kapiler, viskositas, dan gravitasi pada pipa kapiler vertikal telah banyak dilakukan dengan kesimpulan bahwa semakin besar diameter pipa kapiler maka cepat rambat meniscus pada tabung akan semakin lambat, dengan viskositas dan gravitasi yang turut mempengaruhi laju rambat meniscus. Pada penelitian ini fluida penetran air diujikan secara eksperimental semu dengan software simulasi untuk mengetahui Laju Aliran isothermal two-phase flow pada pipa kapiler divergen berorientasi vertikal dengan jari-jari atas $0,0596 \mathrm{~cm} ; 0.0894 \mathrm{~cm}$; dan $0,1192 \mathrm{~cm}$. Didapatkan bahwa sesuai dengan penelitian sebelumnya, semakin besar jari-jari pipa kapiler maka semakin lambat laju aliran, serta ditemukan bahwa selisih slope laju aliran akan semakin kecil seiring bertamabah besarnya jari-jari pipa kapiler.
\end{abstract}

Kata kunci: Air, Axis symmetry, Isothermal two-phase flow, Pipa kapiler, Simulasi.

\section{Pendahuluan}

Banyak jenis mekanisme aliran fluida yang secara progresif telah diteliti sebelum era Renaissance hingga hari ini. Contohnya, fluida paling umum di muka bumi, air, telah dimanfaatkan secara statis seperti pada mesin pres hidrolik hingga secara dinamis seperti pada mekanisme water blasting.

Dari semua studi mengenai mekanika fluida, terdapat satu cabang studi yang sebenarnya memiliki peran cukup banyak pada kehidupan manusia sehari-hari namun kurang mendapatkan perhatian, khususnya di Indonesia, yaitu fenomena kapiler. Studi ini akan berfokus pada fenomena kapiler pada tabung vertikal. Secara umum, terdapat 3 faktor berpengaruh pada fenomena kapiler pada tabung vertikal yang masih memerlukan banyak studi lebih lanjut untuk menambah kekayaan pustaka mengenai fenomena ini, yaitu viskositas cairan penetran, efek gaya gravitasi pada cairan penetran, dan efek bentuk dinding tabung kapiler.

Penelitian terhadap pengaruh bentuk dinding tabung dengan menggunakan metode eksperimen semu telah dilakukan oleh sejumlah peneliti di seluruh dunia, salah satunya Soroush et al [1] yang meneliti pengaruh bentuk dinding kapiler dengan pola gelombang sinusoidal beramplitudo berbeda 
terhadap regime aliran fluida viskus. Hasilnya, tabung kapiler dengan pola sinusoidal dengan amplitudo yang lebih kecil menunjukkan peningkatan terhadap laju aliran fluida. Pada studi ini, akan disampaikan hasil pengujian eksperimental semu pengaruh bentuk dinding kapiler divergen terhadap laju aliran fluida air.

\section{Metode}

Komputasi akan dilakukan menggunakan dua governing equation, yaitu persamaan Navier-Stokes untuk mendeskripsikan transport massa dan momentum, dan juga persamaan tambahan Level-set untuk mendeskripsikan nilai dari gaya tegangan permukaan pada fluida.

Navier-Stokes:

$\rho \frac{\partial u}{\partial t} \rho(u \cdot \nabla) u=\nabla \cdot\left[-p I+\mu\left(\nabla u+(\nabla u)^{T}\right)\right]+F_{s t}+\rho g$

$\nabla \cdot u=0$

$F_{s t}=\nabla \cdot T$

Level-set:

$\frac{\partial \phi}{\partial t}+u \cdot \nabla \phi=\gamma \nabla \cdot\left(\varepsilon \nabla \phi-\phi(1-\phi) \frac{\nabla \phi}{|\nabla \phi|}\right)$

Fukano et al [2], melakukan penelitian terhadap karakteristik aliran isothermal two-phase flow dengan fluida air menggunakan 3 varian diameter pipa kapiler, yaitu $1 \mathrm{~mm}, 2,4 \mathrm{~mm}, 4,9 \mathrm{~mm}$, dan $9 \mathrm{~mm}$. Hasilnya didapatkan bahwa gaya kapiler menjadi signifikan pada ukuran tabung kurang dari 5-9 $\mathrm{mm}$.

Penelitian terhadap karakteristik aliran isothermal two-phase flow dengan fluida air juga dilakukan oleh Mishima et al [3] menggunakan tabung kapiler dengan diameter bervariasi mulai dari 1 hingga $4 \mathrm{~mm}$. hasilnya menunjukkan bahwa kecepatan superfisial dari air pada pipa dengan diameter $1,05 \mathrm{~mm}$ memiliki range $0,153-2,23 \mathrm{~m} / \mathrm{s}$.

Liou et al [4] melakukan esperimen experimental semu untuk menguji pengaruh perubahan luas penampang dinding kapiler terhadap laju aliran isothermal two-phase flow. Hasilnya menunjukkan bahwa kecepatan rambat fluida pada bagian dinding yang konvergen lebih cepat dari laju aliran pada dinding divergen. Serta semua liquid-gas interface berhenti pada bagian divergen

Walls et al [5] melakukan serangkian eksperimen eksperimental dan eksperimental semu terhadap gerak kapiler pada fluida-fluida viskus. Hasilnya menunjukkan bahwa gravitasi dan viskositas akan turut mempengaruhi bentuk aliran isothermal two-phase flow.

Sebagai acuan untuk validasi data, hasil dari penelitian eksperimental dari Jeje et al [6] digunakan sebagai pembanding hasil simulasi. Simulasi validasi dilakukan dengan membuat model geometri axis-symetric dengan bentuk penampang lingkaran sehingga hasil yang didapatkan pada bentuk 3D adalah tabung. Tinggi tabung ditetapkan sebesar $4 \mathrm{~cm}$ karena hasil dari eksperimen menunjukkan kenaikan fluida kapiler melandai pada ketinggian $3 \mathrm{~cm}$. adapun bentuk geometri model eksperimental semu ditunjukkan pada Gambar 1.

Hasil dari simulasi dengan boundary condition yang dibuat sama dengan keadaan eksperimental, meliputi diameter pipa, temperatur fluida, dan jenis fluida dibandingkan dengan data yang didapatkan dari pengujian. Data hasil simulasi disandingkan dengan data dari pengujian pada grafik perbandingan jarak rambat meniscus terhadap waktu seperti pada Gambar 2. 


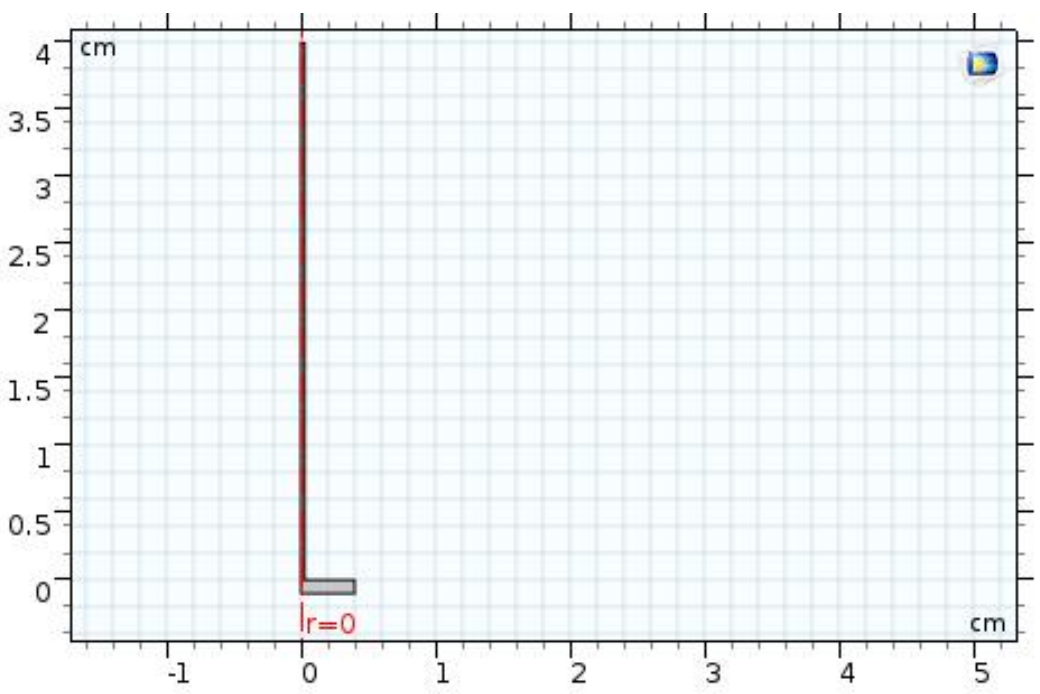

Gambar 1. Bentuk geometri model

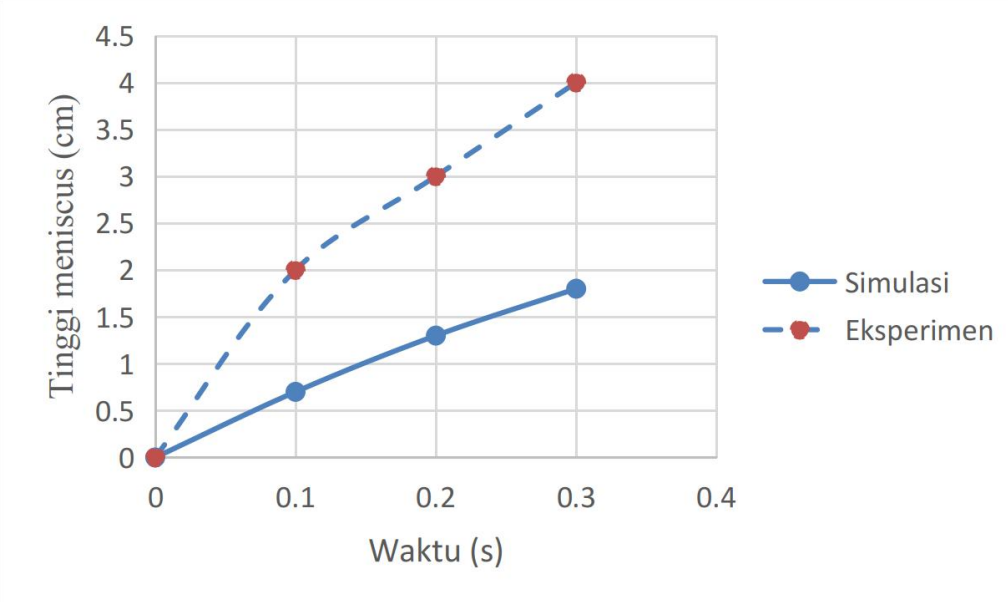

Gambar 2. Grafik perbandingan jarak rambat meniscus terhadap waktu

Pada grafik tersebut dapat dilihat bahwa hasil simulasi tidak sama dengan hasil ekperimen, namun memiliki kecenderungan yang sama. Walaupun tiga faktor besar yang menentukan aliran kapiler seperti percepatan gravitasi, viskositas dan diameter telah dibuat sama, namun nyatanya perbedaan tetap terjadi. Hal ini dimungkinkan oleh sebab awal aliran kapiler dapat terjadi, yakni karena adanya gaya tarik antar molekul pada dinding tabung dengan fluida serta fluida dengan fluida yang tidak dapat digambarkan pada governing equation. Sehinga hasil dari penelitian ini harus dinormalisasi terlebih dahulu agar perkiraan yang dihasilkan bisa lebih baik.

Data akan disajikan dalam bentuk grafik perbandingan jarak rambat meniscus terhadap waktu sehingga slope dari grafik berupa kelajuan dari aliran fluida seperti pada gambar 2. Diagram alir penelitian akan ditampilkan pada Gambar 3 sebagai berikut. 


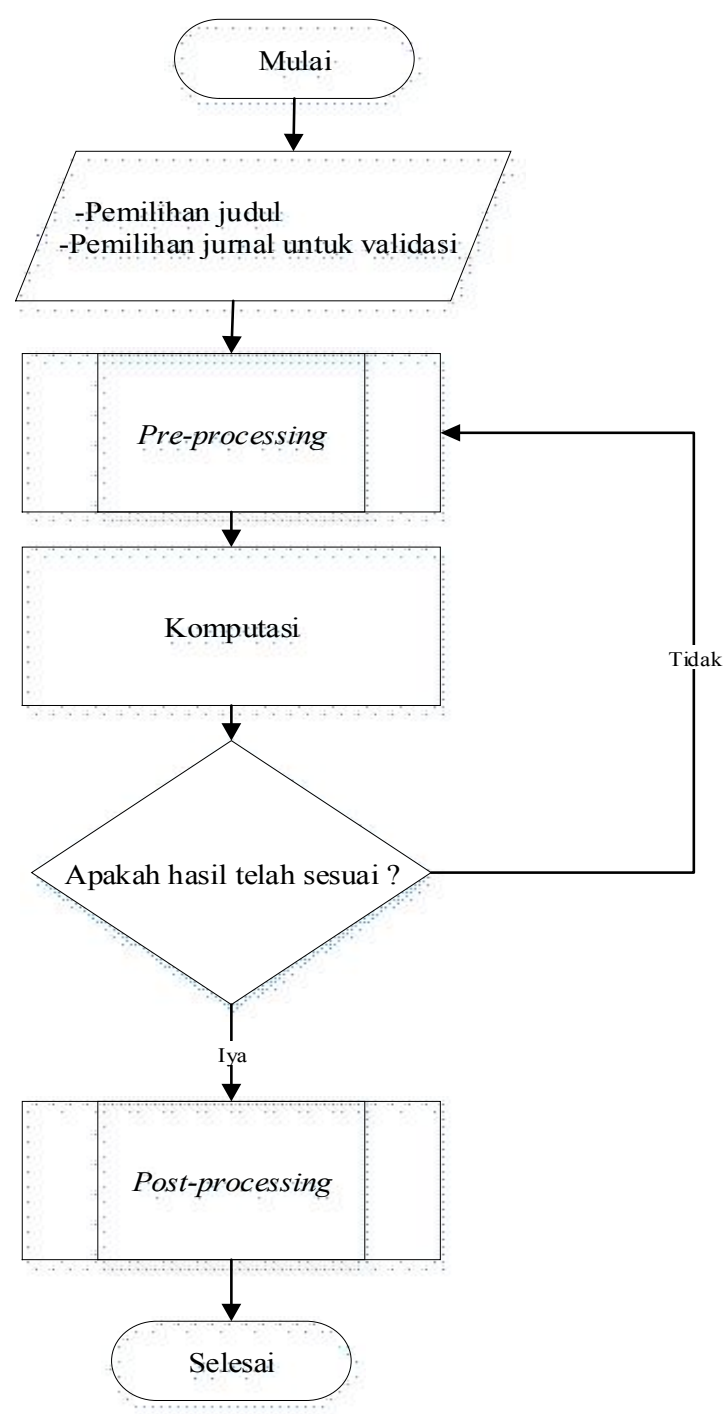

Gambar 3. Diagram alir

\section{Hasil dan Pembahasan}

Pada grafik yang terdapat pada Gambar 4,s dilihat bahwa terdapat 3 variasi jari-jari, yaitu $0,0596 \mathrm{~cm}, 0,0894 \mathrm{~cm}$, dan $0,1192 \mathrm{~cm}$. Pada sumbu y adalah tinggi meniscus $(\mathrm{cm})$ dan sumsbu $\mathrm{x}$ adalah waktu (s). ketiganya terlihat memiliki kecenderungan yang sama yaitu peningkatan secara linear. Kecinderungan tersebut disebabkan karena fokus data terletak pada tinggi rambat meniscus dibawah $1 \mathrm{~cm}$, sehingga belum terlihat perlambatan yang signifikan akibat penumpukan massa fluida penetran.

Terlihat bahwa slope grafik pipa kapiler dengan jari-jari $0,0596 \mathrm{~cm}$ menjadi yang paling curam diantara ketiga pipa kapiler divergen, diikuti oleh pipa jari-jari $0,0894 \mathrm{~cm}$ dan yang paling landai adalah pipa dengan jari-jari sebesar $0,1192 \mathrm{~cm}$. dapat dilihat pula bahwa selisih slope pipa dengan jari-jari $0,0596 \mathrm{~cm}$ cukup jauh dari 2 pipa yang lain, namun selisih slope dua pipa sisanya tidak terlalu jauh. Selisih besar jari-jari dari ketiga pipa dibuat sama yaitu sebesar jari-jari pipa kapiler untuk model validasi, $0,0298 \mathrm{~cm}$, sehingga suatu fenomena dapat diamati, yaitu penurunan selisih slope pada pipa kapiler seiring bertambahnya besar jari-jari.

Meniscus adalah lapisan tempat bertemunya dua fase fluida, dalam penelitian ini adalah air dan udara. Karena orientasi pipa yang vertikal, menyebabkan aliran rammbatan meniscus untuk berjalan kearah atas. Bentuk meniscus pada penelitian ini ditunjukkan pada Gambar 5, (a)-(c). 


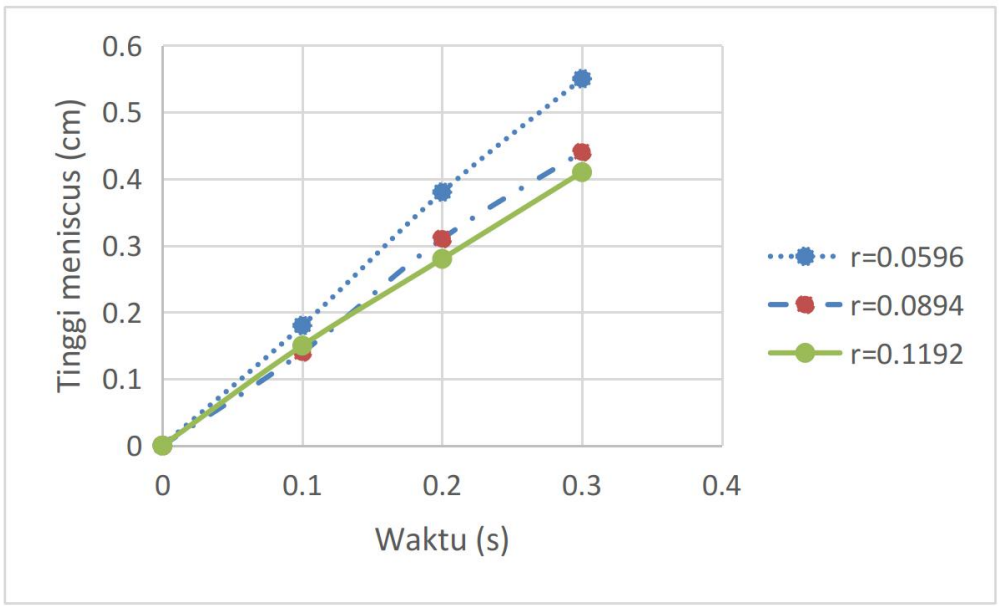

Gambar 4. Grafik perbandingan jarak rambat meniscus terhadap waktu hasil simulasi

Time $=0.3 \mathrm{~s}$ Surface: Volume fraction of fluid 1 ( 1 Contour: Volume fraction of fluid 1 (1)

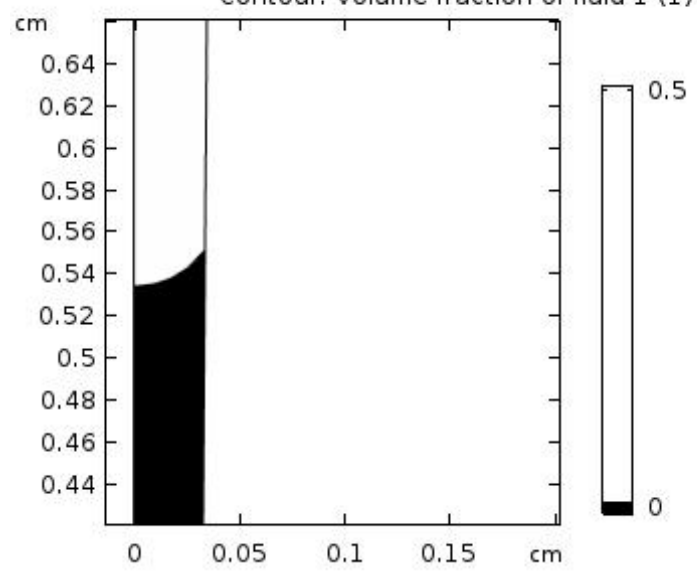

(a)

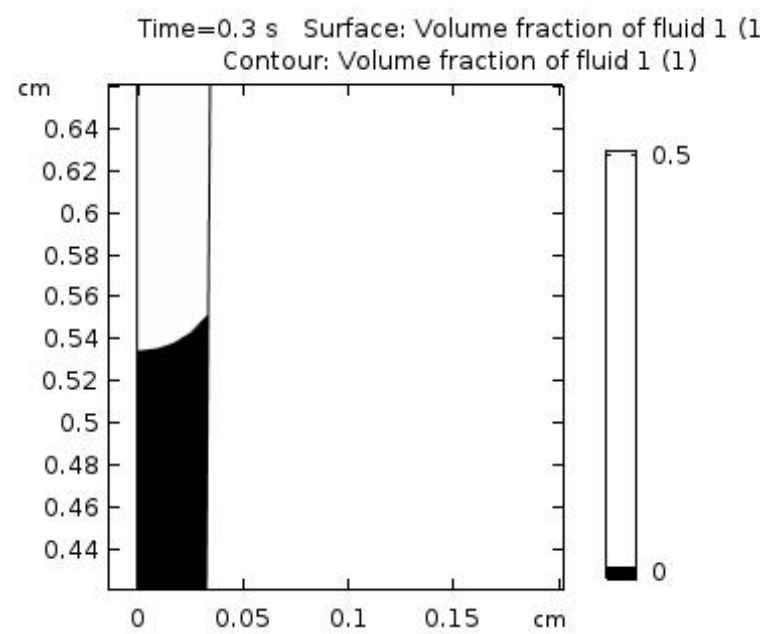

(b)

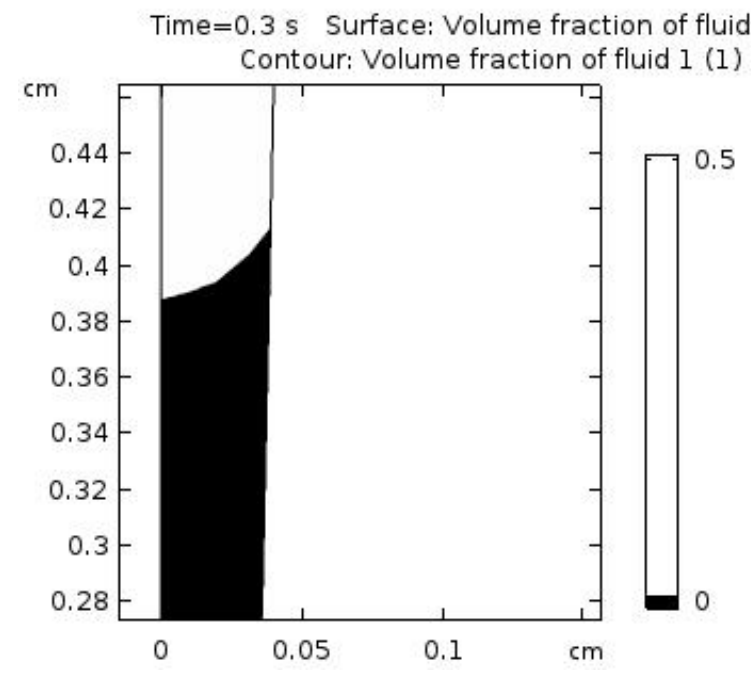

(c)

Gambar 5. (a) Meniscus pipa $r=0.0596 \mathrm{~cm}$, (b) meniscus pipa $r=0,0894 \mathrm{~cm}$, (c) meniscus pipa $\mathrm{r}=0,1192 \mathrm{~cm}$ 


\section{Kesimpulan}

Dari hasil penelitian eksperimental semu pengaruh bentuk dinding kapiler divergen terhadap laju aliran isothermal two-phase flow fluida air dengan variasi jari-jari pipa kapiler sebesar $0,0596 \mathrm{~cm}$, $0,0894 \mathrm{~cm}$, dan 0,1192 $\mathrm{cm}$, dapat ditarik kesimpulan bahwa semakin besar sisi terpanjang dari penampang pipa kapiler divergen dengan fluida penetran air, slope rambatan meniscus akan semakin landai, serta semakin besar sisi terpanjang dari penampang pipa kapiler divergen dengan fluida penetran air, nilai selisih antar-slope pada setiap nilai jari-jari akan semakin kecil.

\section{Referensi}

[1] Soroush. F.," Effect of Capillary Tube's Shape on Capillary Rising Regime for Viscos Fluids," IOP. Conf. Ser.: Mater. Sci. Eng. vol. 300, no. 1, Jan. 2016.

[2] Fukano et al.," Characteristics of Gas-Liquid Two-Phase Flow In A Capillary Tube," Sci. Dir: Jour. of Coll. and Int. Sci., vol. 141, no. 59, p. 68, Okt. 1992.

[3] Mishima. K.," Some Characteristics of Air-Water Two-Phase Flow In Small Diameter Vertical Tubes," Sci. Dir: Int. J. Multiphase Flow, vol. 22, no. 4, p. 703-712, Jan. 1996.

[4] Liou. W. W.," Analytical Modeling of Capillary Flow In Tubes Of Nonuniform Cross Section," Sci. Dir: Jour. of Coll. and Int. Sci., vol. 333, no. 389, p. 68, Jan. 2009.

[5] Walls. Peter. L. L., " Capillary displacement of viscous liquids," Lang., DOI: 10.1021/acs.langmuir.6b00351.

[6] Jeje. A. A.," Rates of Spontaneous Movement of Water in Capillary Tubes," Sci. Dir: Jour. of Coll. and Int. Sci., Vol. 69, No. 3, May. 1979. 